\title{
MODEL PERSAMAAN STRUKTURAL TINGKAT KEPUASAN MASYARAKAT TERHADAP KUALITAS PELAYANAN JALAN TOL BALI MANDARA
}

\author{
I Putu Agus Widhiantara ${ }^{\S 1}$, I Komang Gde Sukarsa ${ }^{2}$, I Putu Eka N. Kencana ${ }^{3}$ \\ ${ }^{1}$ Jurusan Matematika, Fakultas MIPA, Universitas Udayana [Email: aguswidhiantara93@gmail.com] \\ ${ }^{2}$ Jurusan Matematika, Fakultas MIPA, Universitas Udayana [Email: sukarsakomang@yahoo.com] \\ ${ }^{3}$ Jurusan Matematika, Fakultas MIPA, Universitas Udayana [Email: i.putu.enk@gmail.com] \\ ${ }^{\S}$ Corresponding Author
}

\begin{abstract}
The aim of this research is to determine public satisfaction level for the quality of Bali Mandara Highway service and to determine the dominant variable influencing public satisfaction level. This research implemented by using Structural Equation Modeling Partial Least Square (SEM-PLS) and Servqual model. This research was conducted in Badung Regency in the period of March to June 2015. Data were collected by using questionnaires that were distributed directly to 150 users of respondents. The result shows that the public haven't been satisfied with service quality provided by Jasamarga. Meanwhile the empathy, responsiveness and tangible are significantly influencing public satisfaction level to Bali Mandara Highway service quality. We also showed that empathy provide a dominant influence to public satisfaction level.
\end{abstract}

Keywords: Structural Equation Modeling Partial Least Square, service quality, public satisfaction level.

\section{PENDAHULUAN}

Badung merupakan salah satu kabupaten yang memiliki jumlah penduduk cukup besar di Provinsi Bali. Kabupaten ini sebagai salah satu pusat kegiatan pemerintahan dan lokasi dari Bandara Internasional Ngurah Rai. Pesatnya perkembangan aktivitas pariwisata ini menyebabkan intensitas kegiatan masyarakat di Badung cukup tinggi, sehingga berpotensi menimbulkan kemacetan terutama di jalan menuju atau dari bandara serta obyek wisata. Kemacetan yang terjadi di beberapa tempat mengindikasikan bahwa diperlukan jaringan jalan yang baik atau jalan alternatif yaitu jalan tol.

Jalan tol Nusa Dua-Ngurah Rai-Benoa yang lebih dikenal dengan nama Jalan Tol Bali Mandara merupakan jalan tol pertama yang ada di Bali dan dikelola oleh PT. Jasa Marga Bali Tol dengan panjang mencapai $12 \mathrm{~km}$. Jalan tol ini telah beroperasi sejak tanggal 27 September 2013 yang perencanaan pembuatannya adalah untuk memberikan layanan kenyamanan, efisiensi dan keamanan bagi masyarakat. Namun pada kenyataannya, masih banyak pelayanan yang belum memuaskan masyarakat pengguna jalan sehingga dalam penelitian ini akan diukur mengenai tingkat kepuasan masyarakat terhadap kualitas pelayanan Jalan Tol Bali Mandara.

Terdapat beberapa metode kuantitatif yang dapat digunakan untuk mengukur tingkat kepuasan masyarakat, di antaranya adalah dengan Structural Equation Modeling, Multiple Logistic Regression, Gesca, dan Generalized Maximum Entropy. Dalam penelitian ini, tingkat kepuasan masyarakat terhadap kualitas pelayanan Jalan Tol Bali Mandara akan diukur dengan Structural Equation Modeling (SEM). SEM atau model persamaan struktural merupakan analisis multivariat untuk menganalisis hubungan antara variabel secara 
kompleks. Alasan menggunakan SEM adalah karena metode ini memiliki beberapa keunggulan yaitu SEM mempunyai kemampuan untuk mengestimasi hubungan antar variabel yang bersifat multiple relationship, SEM cukup akurat untuk menganalisis data kuesioner yang melibatkan persepsi, dan SEM mampu menganalisis hubungan timbal balik secara serempak (Dillala [1]).

Selain menggunakan SEM, dalam penelitian ini juga menggunakan metode kualitatif yaitu Servqual. Model Servqual adalah suatu metode yang digunakan untuk mengukur tingkat kepuasan layanan terhadap kualitas pelayanan. Model ini mendefinisikan atribut pengukuran kualitas pelayanan jasa yang mewakili 5 dimensi, yaitu Tangible, Reliability, Responsiveness, Assurance, dan Empathy (Parasuraman, Zeithmal, \& Berry [4]).

Penelitian sebelumnya mengenai tingkat kepuasan masyarakat pernah dilakukan oleh I Made Ardhika pada tahun 2007 yang mengukur tingkat kepuasan pelayanan pengguna Jalan Tol Jagorawi dengan pendekatan Servqual dan metode Important-Peformance Analyze (IPA) serta penelitian Albertin Yunita Nawangsari pada tahun 2011 yang menghitung indeks kepuasan pelanggan yaitu mahasiswa FMIPA UNY terhadap operator IM3 dengan melibatkan variabel kualitas, harga dan kepuasan dalam pengujiannya.

Structural Equation Modeling (SEM) merupakan analisis multivariat yang dapat menganalisis hubungan variabel secara kompleks. SEM pertama kali dikembangkan oleh Joreskog pada tahun 1973. SEM merupakan kombinasi dari analisis jalur (path) dan analisis regresi yang memungkinkan peneliti untuk menguji rangkaian hubungan yang saling terkait antara variabel terukur dengan variabel laten (Hair, et al. [2]. SEM dapat dibedakan menjadi dua, yaitu SEM yang berbasis kovarians (covariance based SEM) dan SEM yang berbasis varians atau komponen (component based SEM). Untuk dapat menggunakan SEM berbasis varians seperti SEM PLS ini terdapat beberapa asumsi yaitu ukuran sampel yang digunakan tidak relatif besar, data tidak harus menyebar normal, dan indikator yang digunakan dapat bersifat reflektif maupun formatif (Hair, et al [3]).

Pengujian model persamaan struktural dilakukan untuk mencari model yang fit. Untuk memeriksa model fit digunakan uji kecocokan model. Pertama, untuk model pengukuran (outer model) meliputi: (1) Convergent validity yaitu korelasi antara skor indikator reflektif dengan skor variabel latennya dalam hal ini loading factor 0,5 sampai 0,6 dianggap cukup, pada jumlah indikator per konstruk berkisar antara 3 sampai 7 indikator; (2) Discriminant validity yaitu apabila nilai akar kuadrat Average Variance Extracted (AVE) konstruk lebih besar dari korelasi dengan seluruh konstruk lainnya maka dapat dikatakan bahwa model baik. Nilai pengukuran yang direkomendasikan adalah $\sqrt{\mathrm{AVE}}>0,50$ (Hair, et al [3]):

$$
A V E=\frac{\sum \lambda_{i}^{2}}{\sum \lambda_{i}^{2}+\sum \operatorname{var}\left(\varepsilon_{i}\right)}
$$

(3) Composite reliability ( $\rho c$ ) yaitu kelompok indikator yang mengukur suatu variabel, nilai reliabilitas komposit baik jika $\rho c \geq 0,7$ (Hair, et al [3]).

$$
\rho c=\frac{\left(\sum \lambda_{i}\right)^{2}}{\left(\sum \lambda_{i}\right)^{2}+\sum_{i} \operatorname{var}\left(\varepsilon_{i}\right)}
$$

Selanjutnya, untuk model struktural (inner model), fit model diukur menggunakan $R$ square $\left(R^{2}\right) . R^{2}$ digunakan untuk mengukur seberapa baik nilai observasi dihasilkan oleh model dan juga estimasi parameternya. Besaran $R^{2}$ memiliki nilai $0<\mathrm{R}^{2}<1$, nilai yang semakin mendekati 1 berarti model semakin baik (Hair, et al [3]).

Model Servqual adalah suatu model yang dikembangkan oleh Parasuraman, Berry, dan Zithmal [4] yang digunakan untuk mengukur tingkat kepuasan layanan terhadap kualitas pelayanan. Model Servqual juga dikenal dengan istilah Gap Analysis. Model ini mengukur kualitas jasa secara kuantitatif dalam bentuk kuesioner dan dimensi-dimensi kualitas pelayanan.

Ada beberapa keunggulan dari model 
Servqual yang membuat model ini banyak diterapkan, yaitu model Servqual telah menjadi standar penilaian atas berbagai dimensi kualitas pelayanan, berbagai riset telah menunjukkan bahwa instrumen model Servqual valid dan handal untuk berbagai konteks layanan, dan model Servqual memiliki prosedur baku yang memudahkan interpretasi hasil. Menurut Parasuraman, Berry, dan Zithmal [4], model Servqual mempunyai 5 dimensi, yaitu: (1) Kondisi fisik (Tangible) meliputi fasilitas fisik, perlengkapan dan penampilan dari petugas; (2) Kehandalan (Reliability) meliputi kemampuan memberikan pelayanan dengan sigap dan akurat; (3) Tanggung jawab (Responsiveness) meliputi kewajiban membantu masyarakat dan melayani dengan tanggap; (4) Jaminan (Assurance) meliputi kemampuan, pengetahuan, dan sikap petugas yang dapat dipercaya; (5) Kepedulian (Empathy) meliputi hubungan komunikasi yang baik, pemberian informasi, dan pentingnya usaha untuk mengetahui kebutuhan dari masyarakat.

\section{METODE PENELITIAN}

Penelitian ini dilakukan di Kabupaten Badung dengan obyek Jalan Tol Bali Mandara. Waktu penelitian dilaksanakan pada periode Maret sampai Juni 2015. Pengumpulan data dilakukan dengan menggunakan kuesioner yang disebarkan langsung kepada 150 masyarakat pengguna Jalan Tol Bali Mandara sebagai responden. Kemudian, kuesioner yang telah dijawab oleh responden akan diuji kelayakannya dengan uji validitas dan uji reliabilitas. Kuesioner tersebut menggunakan skala Likert.

Data yang diperoleh dalam penelitian ini dianalisis menggunakan metode SEM dengan software SmartPLS. Langkah-langkahnya sebagai berikut: (1) Pengembangan model teoritis; (2) Pengembangan diagram jalur; (3) Konversi diagram jalur ke dalam persamaan:

$$
\begin{aligned}
& K M=\gamma_{11} K F+\gamma_{12} K H+\gamma_{13} T J+\gamma_{14} J N+ \\
& \gamma_{15} K P+\zeta_{1}
\end{aligned}
$$

Misalkan, variabel laten kondisi fisik (KF) diukur dengan lima indikator $\mathrm{X}_{1}, \mathrm{X}_{2}, \mathrm{X}_{3}, \mathrm{X}_{4}$, dan $\mathrm{X}_{5}$ :

$$
\begin{aligned}
& X_{1}=\lambda_{11} K F+\varepsilon_{1} \\
& X_{2}=\lambda_{21} K F+\varepsilon_{2} \\
& X_{3}=\lambda_{31} K F+\varepsilon_{3} \\
& X_{4}=\lambda_{41} K F+\varepsilon_{4} \\
& X_{5}=\lambda_{51} K F+\varepsilon_{5}
\end{aligned}
$$

(4) Estimasi model; (5) Evaluasi Goodness of Fit; (6) Pengujian hipotesis $\left(\mathrm{H}_{1}, \mathrm{H}_{2}, \mathrm{H}_{3}, \mathrm{H}_{4}\right.$, dan $\mathrm{H}_{5}$ ) yang selanjutnya dilakukan interpretasi

\begin{tabular}{|c|c|c|}
\hline Variabel & Kategori & Persentase $(\%)$ \\
\hline \multirow{2}{*}{$\begin{array}{l}\text { Jenis } \\
\text { Kelamin }\end{array}$} & Laki-laki & 55.3 \\
\hline & Perempuan & 44.7 \\
\hline \multirow[t]{4}{*}{ Umur } & 18-25 tahun & 27.3 \\
\hline & 26-35 tahun & 34.7 \\
\hline & 36-45 tahun & 30.7 \\
\hline & $>45$ tahun & 7.3 \\
\hline \multirow{4}{*}{$\begin{array}{l}\text { Pendidikan } \\
\text { Terakhir }\end{array}$} & SD & 0.7 \\
\hline & SMP & 8.7 \\
\hline & $\begin{array}{l}\text { SMA/SMK/ } \\
\text { sederajat }\end{array}$ & 82.6 \\
\hline & $\begin{array}{l}\text { Diploma/ } \\
\text { Sarjana }\end{array}$ & 8.0 \\
\hline \multirow[t]{4}{*}{ Pekerjaan } & $\begin{array}{l}\text { Pelajar/ } \\
\text { Mahasiswa }\end{array}$ & 16.0 \\
\hline & PNS & 8.0 \\
\hline & Swasta & 57.3 \\
\hline & Lainnya & 18.7 \\
\hline \multirow{2}{*}{$\begin{array}{l}\text { Jenis } \\
\text { Kendaraan }\end{array}$} & Roda empat & 53.3 \\
\hline & Roda dua & 46.7 \\
\hline \multirow{5}{*}{$\begin{array}{l}\text { Tingkat } \\
\text { Penggunaan }\end{array}$} & $3 \mathrm{kali} / \mathrm{minggu}$ & 32.7 \\
\hline & $4 \mathrm{kali} / \mathrm{minggu}$ & 30.7 \\
\hline & $5 \mathrm{kali} / \mathrm{minggu}$ & 13.3 \\
\hline & $6 \mathrm{kali} / \mathrm{minggu}$ & 15.3 \\
\hline & $\begin{array}{l}>6 \mathrm{kali} / \\
\text { minggu }\end{array}$ & 8.0 \\
\hline
\end{tabular}
model.

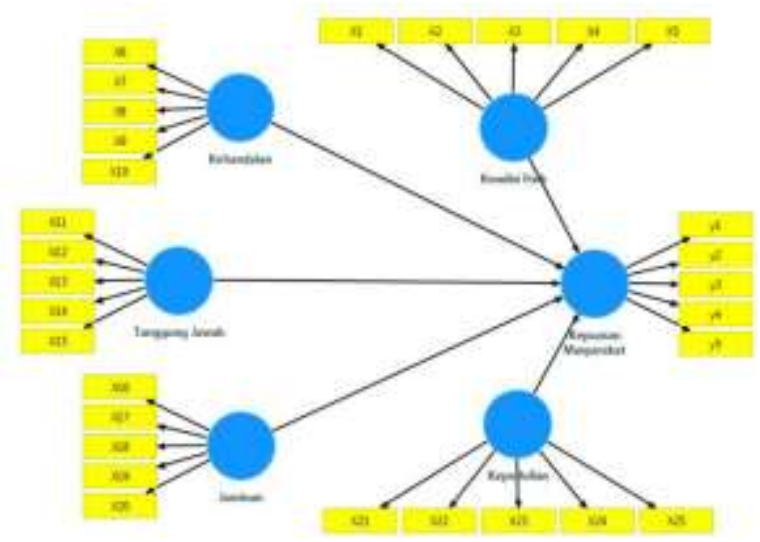

Gambar 1. Rancangan Model Persamaan Struktural pada Penelitian

\section{HASIL DAN PEMBAHASAN}

Tabel 1 Profil Responden 
Berdasarkan hasil pada Tabel 1 dapat dilihat bahwa responden masyarakat yang berpartisipasi dalam pengisian kuesioner penelitian ini $55.3 \%$ berjenis kelamin laki-laki dan $44.7 \%$ berjenis kelamin perempuan. Dari 150 responden yang diambil, terdapat $34.7 \%$ masyarakat berumur 26-35 tahun, $82.6 \%$ dengan pendidikan terakhir SMA/SMK/ Sederajat, dan $57.3 \%$ berstatus swasta.

Selanjutnya dilakukan uji kelayakan instrumen, yaitu uji validitas dan uji reliabilitas dari 30 item pernyataan yang digunakan pada kuesioner penelitian. Adapun hasil yang diperoleh dengan bantuan program SPSS, dapat dilihat dalam tabel 2.

Tabel 2. Nilai Cronbach Alpha dan Korelasi Item-Total Dikoreksi dari Kondisi Fisik

\begin{tabular}{|c|l|c|}
\hline & \multicolumn{1}{|c|}{ Indikator } & $\begin{array}{c}\text { Corr }_{\text {total }} \\
\text { item }\end{array}$ \\
\hline X1 & $\begin{array}{l}\text { Penampilan dan kerapian } \\
\text { petugas }\end{array}$ & .483 \\
\hline X2 & $\begin{array}{l}\text { Kebersihan dan penataan } \\
\text { jalan }\end{array}$ & .479 \\
\hline X3 & $\begin{array}{l}\text { Tanjakan, turunan, dan } \\
\text { tikungan jalan }\end{array}$ & .470 \\
\hline X4 & $\begin{array}{l}\text { Kualitas permukaan jalan } \\
\text { yang rata dan tidak licin }\end{array}$ & .398 \\
\hline X5 & $\begin{array}{l}\text { Kelengkapan fasilitas } \\
\text { jalan tol }\end{array}$ & .439 \\
\hline & Cronbach's Alpha & .698 \\
\hline
\end{tabular}

Memperhatikan Tabel 2, dapat dilihat bahwa semua item pernyataan valid untuk mengukur kondisi fisik karena memiliki nilai corr $_{\text {total-item }}>0.30$. Adapun nilai Cronbach's Alpha sebesar $0.698>0.60$ menyatakan bahwa instrumen pengukuran yang digunakan untuk mengukur kondisi fisik dapat dipercaya.

Berdasarkan Tabel 3, dapat dilihat bahwa semua item pernyataan valid untuk mengukur kehandalan karena memiliki nilai corr $_{\text {total-item }}>$ 0.30. Adapun nilai Cronbach's Alpha sebesar $0.709>0.60$ menyatakan bahwa instrumen pengukuran yang digunakan untuk mengukur kehandalan dapat dipercaya.
Tabel 3. Nilai Cronbach Alpha dan Korelasi Item-Total Dikoreksi dari Kehandalan

\begin{tabular}{|c|c|c|}
\hline & Indikator & Corr $_{\text {total-item }}$ \\
\hline $\mathrm{X} 6$ & $\begin{array}{l}\text { Petugas sigap dalam } \\
\text { memberikan layanan } \\
\text { transaksi }\end{array}$ & .388 \\
\hline $\mathrm{X} 7$ & $\begin{array}{l}\text { Kesigapan petugas saat } \\
\text { terjadi masalah di } \\
\text { tengah jalan tol }\end{array}$ & .511 \\
\hline $\mathrm{X} 8$ & $\begin{array}{l}\text { Pelayanan yang } \\
\text { diberikan tepat sasaran } \\
\text { atau sesuai dengan yang } \\
\text { diminta pengguna }\end{array}$ & .489 \\
\hline X9 & $\begin{array}{l}\text { Perawatan jalan tol oleh } \\
\text { pihak Jasa Marga }\end{array}$ & .541 \\
\hline $\mathrm{X} 10$ & $\begin{array}{l}\text { Kondisi arus lalu lintas } \\
\text { jalan tol lancar }\end{array}$ & .416 \\
\hline & Cronbach's Alpha & .709 \\
\hline
\end{tabular}

Memperhatikan Tabel 4, dapat dilihat bahwa terdapat satu item pernyataan yaitu X13 yang tidak valid untuk mengukur tanggung jawab karena memiliki nilai corr $_{\text {total-item }}<0.30$. Adapun nilai Cronbach's Alpha sebesar $0.640>$ 0.60 menyatakan bahwa instrumen pengukuran yang digunakan untuk mengukur tanggung jawab dapat dipercaya.

Tabel 4. Nilai Cronbach Alpha dan Korelasi Item-Total Dikoreksi dari Tanggung Jawab

\begin{tabular}{|c|l|c|}
\hline & \multicolumn{1}{|c|}{ Indikator } & $\begin{array}{c}\text { Corr }_{\text {total }} \\
\text { item }\end{array}$ \\
\hline X11 & $\begin{array}{l}\text { Kejelasan fungsi rambu- } \\
\text { rambu lalu lintas }\end{array}$ & .400 \\
\hline X12 & $\begin{array}{l}\text { Petugas tidak } \\
\text { menunjukkan kesan } \\
\text { sibuk dalam menyambut } \\
\text { pelanggan }\end{array}$ & .455 \\
\hline X13 & $\begin{array}{l}\text { Perbaikan dari pihak } \\
\text { Jasamarga ketika terjadi } \\
\text { kerusakan jalan }\end{array}$ & .277 \\
\hline X14 & $\begin{array}{l}\text { Pengontrolan arus lalu } \\
\text { lintas oleh petugas } \\
\text { patroli }\end{array}$ & .335 \\
\hline X15 & $\begin{array}{l}\text { Pengoperasian seluruh } \\
\text { gardu tol pada jam-jam } \\
\text { sibuk }\end{array}$ & .514 \\
\hline \multicolumn{1}{|l|}{ Cronbach's Alpha } & .640 \\
\hline
\end{tabular}


Tabel 5. Nilai Cronbach Alpha dan Korelasi Item-Total Dikoreksi dari Jaminan

\begin{tabular}{|l|l|c|}
\hline & \multicolumn{1}{|c|}{ Indikator } & $\begin{array}{c}\text { Corr }_{\text {total }} \\
\text { item }\end{array}$ \\
\hline X16 & $\begin{array}{l}\text { Kondisi jalan tol yang } \\
\text { aman }\end{array}$ & .461 \\
\hline X17 & $\begin{array}{l}\text { Akurasi atau ketepatan } \\
\text { pengembalian uang di } \\
\text { gardu tol }\end{array}$ & .520 \\
\hline X18 & $\begin{array}{l}\text { Keamanan keselamatan } \\
\text { dalam menggunakan } \\
\text { jalan tol }\end{array}$ & .495 \\
\hline X19 & $\begin{array}{l}\text { Tersedianya kendaraan } \\
\text { pengangkut dan derek }\end{array}$ & .365 \\
\hline X20 & $\begin{array}{l}\text { Keakuratan informasi } \\
\text { yang diberikan }\end{array}$ & .439 \\
\hline \multicolumn{2}{|l|}{ Cronbach's Alpha } & .700 \\
\hline
\end{tabular}

Memperhatikan Tabel 5, dapat dilihat bahwa semua item pernyataan valid untuk mengukur jaminan karena memiliki nilai corr $_{\text {total-item }}>0.30$. Adapun nilai Cronbach's Alpha sebesar $0.700>0.60$ menyatakan bahwa instrumen pengukuran yang digunakan untuk mengukur jaminan dapat dipercaya.

Tabel 6. Nilai Cronbach Alpha dan Korelasi Item-Total Dikoreksi Kepedulian

\begin{tabular}{|c|l|c|}
\hline & \multicolumn{1}{|c|}{ Indikator } & Corr $_{\text {total-item }}$ \\
\hline X21 & $\begin{array}{l}\text { Keramahan petugas } \\
\text { saat melayani }\end{array}$ & .600 \\
\hline X22 & $\begin{array}{l}\text { Kemudahan } \\
\text { mendapatkan } \\
\text { pelayanan }\end{array}$ & .584 \\
\hline X23 & $\begin{array}{l}\text { Perhatian petugas } \\
\text { terhadap keluhan } \\
\text { pengguna jalan }\end{array}$ & .477 \\
\hline X24 & $\begin{array}{l}\text { Petugas selalu } \\
\text { mengucapkan terima } \\
\text { kasih di akhir } \\
\text { pelayanan }\end{array}$ & .578 \\
\hline X25 & $\begin{array}{l}\text { Kejujuran petugas } \\
\text { dalam pembayaran tol }\end{array}$ & .481 \\
\hline & Cronbach's Alpha & .770 \\
\hline
\end{tabular}

Memperhatikan Tabel 6, dapat dilihat bahwa semua item pernyataan valid untuk mengukur kepedulian karena memiliki nilai corr $_{\text {total-item }}>0.30$. Adapun nilai Cronbach's Alpha sebesar $0.770>0.60$ menyatakan bahwa instrumen pengukuran yang digunakan untuk mengukur kepedulian dapat dipercaya.
Tabel 7. Nilai Cronbach Alpha dan Korelasi Item-Total Dikoreksi Kepuasan Masyarakat

\begin{tabular}{|c|c|c|}
\hline & Indikator & $\begin{array}{c}\text { Corr }_{\text {total }} \\
\text { item }\end{array}$ \\
\hline Y1 & $\begin{array}{l}\text { Perasaan senang dengan } \\
\text { pelayanan yang diberikan }\end{array}$ & .508 \\
\hline Y2 & $\begin{array}{l}\text { Kesesuaian kondisi riil } \\
\text { dengan harapan }\end{array}$ & .439 \\
\hline Y3 & $\begin{array}{l}\text { Adanya nilai lebih yang } \\
\text { diperoleh ketika } \\
\text { menggunakan jasa jalan } \\
\text { tol }\end{array}$ & .516 \\
\hline Y4 & $\begin{array}{l}\text { Perbandingan harga } \\
\text { dengan kualitas pelayanan }\end{array}$ & .455 \\
\hline Y5 & $\begin{array}{l}\text { Keberadaan jalan tol } \\
\text { bermanfaat bagi pengguna }\end{array}$ & .522 \\
\hline \multicolumn{2}{|r|}{ Cronbach's Alpha } & .724 \\
\hline
\end{tabular}

Memperhatikan Tabel 7, dapat dilihat bahwa semua item pernyataan valid untuk mengukur kepuasan masyarakat karena memiliki nilai corr $_{\text {total-item }}>0.30$. Adapun nilai Cronbach's Alpha sebesar $0.724>0.60$ menyatakan bahwa instrumen pengukuran yang digunakan untuk mengukur kepuasan masyarakat dapat dipercaya.

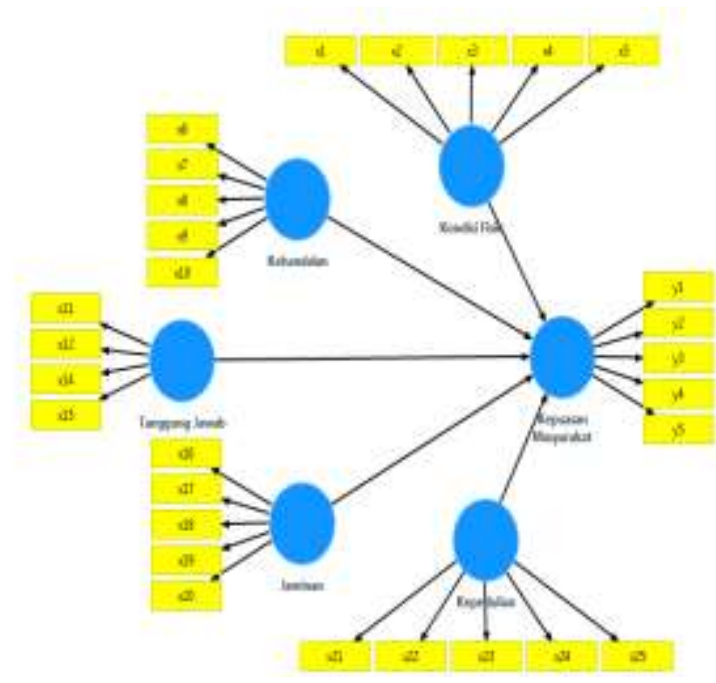

Gambar 2. Model Persamaan Struktural Setelah Melalui Uji Kelayakan Instrumen

Selanjutnya, dengan menggunakan program SmartPLS 3 diperoleh penduga-penduga untuk masing-masing jalur seperti pada Gambar 3. 


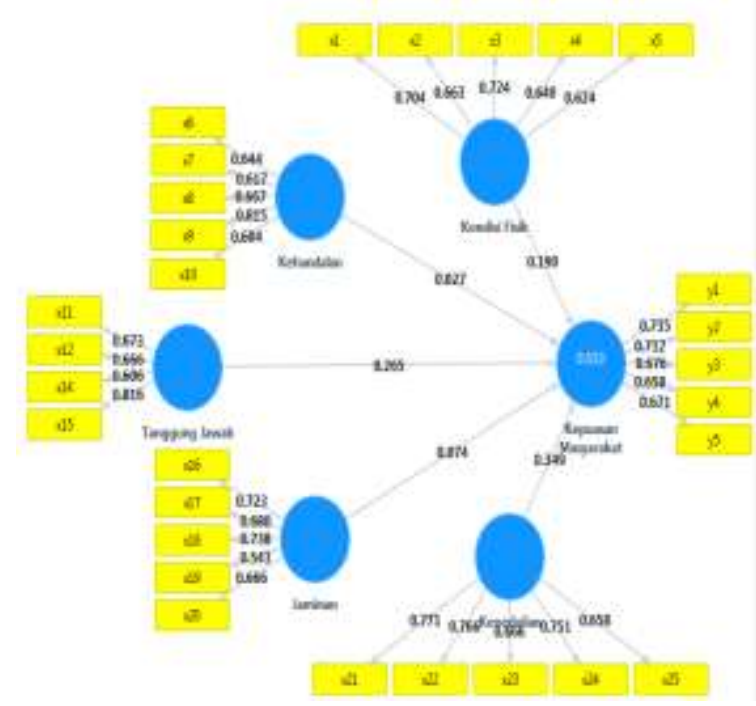

Gambar 3. Model Persamaan Struktural yang Dianalisis dengan Penduga dari MasingMasing Jalur

Tabel 8. Nilai Path Coefficients pada Hubungan antara Variabel Laten

\begin{tabular}{|l|r|r|r|}
\hline \multicolumn{1}{|c|}{$\begin{array}{c}\text { Hubungan } \\
\text { Kausal }\end{array}$} & $\begin{array}{c}\text { Original } \\
\text { Sample }\end{array}$ & $\begin{array}{c}\text { Standard } \\
\text { Error }\end{array}$ & T Stat \\
\hline $\begin{array}{l}\text { Kondisi Fisik } \\
\begin{array}{l}\text { Kepuasan } \\
\text { Masyarakat }\end{array}\end{array}$ & 0.190 & 0.072 & $\begin{array}{r}2.637 \\
(\mathrm{~s})\end{array}$ \\
\hline $\begin{array}{l}\text { Kehandalan } \rightarrow \\
\text { Kepuasan } \\
\text { Masyarakat }\end{array}$ & 0.027 & 0.075 & $\begin{array}{r}0.354 \\
(\mathrm{ts})\end{array}$ \\
\hline $\begin{array}{l}\text { Tanggung } \\
\text { Jawab } \rightarrow\end{array}$ & 0.265 & 0.083 & $\begin{array}{r}3.190 \\
(\mathrm{~s})\end{array}$ \\
$\begin{array}{l}\text { Kepuasan } \\
\text { Masyarakat }\end{array}$ & 0.074 & 0.099 & $\begin{array}{r}0.747 \\
(\mathrm{ts})\end{array}$ \\
\hline $\begin{array}{l}\text { Jaminan } \rightarrow \\
\text { Kepuasan } \\
\text { Masyarakat }\end{array}$ & 0.349 & 0.102 & $\begin{array}{r}3.401 \\
(\mathrm{~s})\end{array}$ \\
\hline $\begin{array}{l}\text { Kepedulian } \rightarrow \\
\text { Kepuasan } \\
\text { Masyarakat }\end{array}$ & & & \\
\hline
\end{tabular}

$*_{s}=$ signifikan; $t s=$ tidak signifikan

Hasil pada Tabel 8 menyatakan bahwa hubungan kausal yang terjadi antara variabel kondisi fisik dengan kepuasan masyarakat, variabel tanggung jawab dengan kepuasan masyarakat, dan variabel kepedulian dengan kepuasan masyarakat memiliki nilai koefisien jalur yaitu masing-masing $0.190,0.265$, dan 0.349 , namun variabel kepedulian yang lebih dominan berpengaruh terhadap kepuasan masyarakat. Ketiga hubungan kausal tersebut memiliki nilai yang signifikan pada taraf uji 5\% (t-statistik > 1.96). Akan tetapi, di sisi lain terdapat dua hubungan kausal yang menunjukkan nilai yang tidak signifikan yaitu hubungan kausal antara variabel kehandalan dengan kepuasan masyarakat dan hubungan kausal antara variabel jaminan dengan kepuasan masyarakat. Hal ini berarti bahwa kehandalan dan jaminan tidak memberikan pengaruh yang signifikan atau nyata terhadap kepuasan masyarakat pengguna Jalan Tol Bali Mandara.

Tabel 9. Nilai Original Sample dari AVE, $\sqrt{\mathrm{AVE}}$ dan Composite Reliability ( $\rho c$ )

\begin{tabular}{|l|c|c|c|c|}
\hline Var. & AVE & $\sqrt{\text { AVE }}$ & $\rho c$ & Ket. \\
\hline KF & 0.451 & 0.672 & 0.804 & Baik \\
\hline KH & 0.454 & 0.674 & 0.804 & Baik \\
\hline TJ & 0.482 & 0.694 & 0.786 & Baik \\
\hline JN & 0.454 & 0.674 & 0.804 & Baik \\
\hline KP & 0.524 & 0.724 & 0.846 & Baik \\
\hline KM & 0.477 & 0.691 & 0.820 & Baik \\
\hline
\end{tabular}

Memperhatikan hasil pada Tabel 9, dapat dilihat bahwa nilai dari akar Average Variance Extracted $(\sqrt{\mathrm{AVE}})$ masing-masing sebesar $0.672,0.674,0.694,0.674,0.724$ dan 0.691 . Semua nilai dari $\sqrt{\mathrm{AVE}}>0.5$ dan nilai Composite Reliability $\geq 0.7$. Kedua hal tersebut menunjukkan bahwa model yang dihasilkan dalam penelitian ini baik dan dapat dipercaya.

Dalam model yang dianalisis, diperoleh juga nilai koefisien determinasi $\left(\mathrm{R}^{2}\right)$ sebesar 0.533 atau 53.3\%. Nilai $R^{2}$ tersebut mengindikasikan bahwa variabel-variabel laten eksogen (kondisi fisik, kehandalan, tanggung jawab, jaminan, dan kepedulian) hanya mampu mewakili variabel laten endogennya (kepuasan masyarakat) sebesar $53.3 \%$ dan sisanya dipengaruhi oleh variabel yang lain.

\section{KESIMPULAN DAN SARAN}

Hasil analisis SEM dalam penelitian ini menunjukkan bahwa masyarakat belum puas dengan kualitas pelayanan yang diberikan dan dari kelima variabel Servqual yang digunakan dalam model, hanya tiga variabel yaitu kepedulian, tanggung jawab, dan kondisi fisik yang berpengaruh signifikan untuk mengukur 
tingkat kepuasan masyarakat terhadap kualitas pelayanan Jalan Tol Bali Mandara.

Variabel yang dominan memengaruhi tingkat kepuasan masyarakat terhadap kualitas pelayanan Jalan Tol Bali Mandara adalah variabel kepedulian karena dari ketiga variabel yang signifikan, kepedulian memberikan pengaruh paling tinggi.

Adapun saran yang dapat disampaikan penulis, yaitu pada penelitian ini interaksi dari variabel belum diperhitungkan dan pengaruh mediasi juga belum dipertimbangkan, diharapkan untuk penelitian selanjutnya agar menambahkan interaksi dan variabel mediasi untuk menyempurnakan model.

\section{DAFTAR PUSTAKA}

[1] Dillala, Lisabeth. 2000. Handbook of Multivariate Statistic and Mathematical Modelling. Illinois: Elsevier Science.

[2] Hair, J. F., Black, W. C., Babin, B. J., \& Anderson, R. E. 2010. Multivariate Data Analysis (Seventh Edition ed.). New Jersey: Pearson Prentice Hall.

[3] Hair, J. F., M. Hult, G. T., Ringle, C. M., \& Sarstedt, M. 2013. A Primer On Partial Least Squares Structural Equation Modeling (PLS-SEM). Los Angeles: SAGE Publications, Inc.

[4] Parasuraman, A, Zeithmal, V.A., \& Berry, L.L. 1988. Servqual: A Multiple-Item Scale for Measuring Consumer Perceptions of Service Quality. Journal of Retailing. 